\title{
Research on the performance and application of low traffic hardened lime-fly ash pavement materials in rural areas
}

\author{
Zhenjun Wang ${ }^{1}$, Jiayuan $\mathrm{He}^{2}$, Chunyi Yuan ${ }^{3}$, Yonghong Zhang ${ }^{4}$ \\ ${ }^{1}$ School of Automobile, Chang'an University, Xi'an, China \\ ${ }^{2,3}$ Transport Planning and Research Institute, Ministry of Transport, Beijing, China \\ ${ }^{4}$ CCCC Infrastructure Maintenance Group Co., Ltd, Beijing, China \\ ${ }^{1}$ Corresponding author

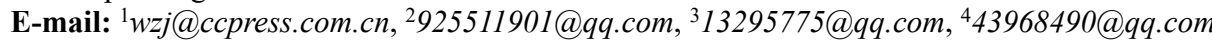

Received 6 June 2018; accepted 13 June 2018 DOI https://doi.org/10.21595/vp.2018.20022

Copyright (C) 2018 Zhenjun Wang, et al. This is an open access article distributed under the Creative Commons Attribution License, which permits unrestricted use, distribution, and reproduction in any medium, provided the original work is properly cited.

\begin{abstract}
By means of curing agent hardening technology applied for lime-fly ash road surface, the performance of unconfined compressive strength, water stability and freezing stability of hardened fly ash mixture has been tested, and the feasibility of the technology has been verified. At the same time, combined with the indoor test results, the test road has been paved which achieved good results, and the construction technology is simple, economical and reasonable, so it has a good value of popularization and application.
\end{abstract}

Keywords: lime-fly ash soil, curing agent, material performance, construction technology.

\section{Introduction}

With the large-scale construction of rural roads, a number of road pavement structures and forms suitable for rural transportation have emerged. Although asphalt and cement concrete pavements have good road performance, their construction costs are high and the construction process is complicated. While the price of gravel pavement is low, it has poor driving effect on rainy days. For areas lacking crushed stones and gravel materials, it instead increases the cost [1]. Considering the existing traffic conditions of some rural roads in underdeveloped areas, the hardened lime-fly ash road surface can be used as the pavement structure in these areas. Therefore, it is necessary to conduct in-depth research on this type of road surface and examine its actual use effect at the same time.

\section{Analysis of formation mechanism of hardened lime-fly ash pavement strength}

Hardening the lime-fly ash mixture with a curing agent is a comprehensive method of consolidation soil, which has both physical and chemical reactions. The physical effects are mainly manifested by mixing and compaction; the chemical reaction is mainly represented by the dissociation reaction of lime in water, the pozzolanic reaction between lime, fly ash and soil, as well as the reaction between the curing agent and the mixture [2-4].

The curing agent is mainly a high-water-soluble polymer emulsion, and is the main film-forming substance in the mixture. It has a high chemical stability $[5,6]$, whose role is to bond the other components together, and adhere to the surface of the coated substrate to form a tough protective film. The reaction of the curing agent to the mixture is illustrated by two processes: one process is that the basic units of the soil are close to each other under the action of the external force and are connected to each other at the interface; secondly, the curing agent hydrates otherwise reacts with the soil to form a gelling property. The hydration products bind the soil particles, so that the soil forms a good whole under the action of the high-molecular polymer, and its strength, water stability, freezing stability, bending strength, etc. have all been improved to different degrees [7-9], thus becoming a new type of pavement material that can be used in rural 
low-traffic roads.

\section{Experimental design for road performance}

\subsection{Raw materials}

\subsubsection{Soil}

The soil used in this project is from Guangyang Township, Yintai District, Tongchuan City, Shaanxi Province, China. The area is located in the gully area of the southern Loess Plateau and the soil belongs to powdery sub-clay. The physical property indicators obtained through the test are shown in Table 1.

Table 1. Physical properties of soil

\begin{tabular}{|c|c|c|c|c|c|}
\hline Color & $\begin{array}{c}\text { Maximum dry } \\
\text { density }\left(\mathrm{g} / \mathrm{cm}^{3}\right)\end{array}$ & $\begin{array}{c}\text { Liquid limit } \\
\text { WL }(\%)\end{array}$ & $\begin{array}{c}\text { Plastic limit } \\
\text { WP }(\%)\end{array}$ & $\begin{array}{c}\text { Plasticity index } \\
\text { IP }(\%)\end{array}$ & Soil classification \\
\hline Yellow & 1.829 & 32.2 & 19.8 & 12.4 & Powdery sub-clay \\
\hline
\end{tabular}

\subsubsection{Lime}

The active material of slaked lime used in this project is $63.4 \%$. According to the technical standard of "Technical Specification for Construction of Highway pavement Base", the lime quality reaches grade II ash, which conforms to the requirement of road use.

\subsubsection{Fly ash}

Table 2. Chemical composition of fly ash

\begin{tabular}{|c|c|c|c|c|c|c|}
\hline Component & $\mathrm{SiO}_{2}(\%)$ & $\mathrm{Al}_{2} \mathrm{O}_{3}(\%)$ & $\mathrm{Fe}_{2} \mathrm{O}_{3}(\%)$ & $\mathrm{CaO}(\%)$ & $\mathrm{MgO}(\%)$ & Ignition loss (\%) \\
\hline Fly ash for test & 49.8 & 26.9 & 5.4 & 2.4 & 1.1 & 10.5 \\
\hline
\end{tabular}

\subsubsection{Curing agent}

Through the comparison and selection of 11 curing products, it was finally determined that the three best curing agents were used in this study, which were recorded as $1 \#, 2 \#$, and 3\#, respectively.

\subsection{Test design}

The suitable mix ratio of base lime-fly ash mixture was determined by the comparison test in the early stage, and then the hardened lime-fly ash pavement specimens with curing agent were tested by road performance test, and the performance of the hardened lime-fly ash pavement was compared with the benchmark test piece. Finally, the optimal combination is determined. Road performance tests mainly include: compressive strength, compressive resilience modulus, water stability and freezing stability.

Table 3. Mixture ratio results of different curing agents

\begin{tabular}{|c|c|}
\hline Type of mixture & (hardening agent: lime: fly ash: soil) \\
\hline Lime fly-ash soil & $0: 8: 22: 70$ \\
\hline $\begin{array}{c}\text { 1\# Hardening agent + Lime fly-ash soil } \\
\text { (abbreviated as 1\# curing agent) }\end{array}$ & $0.2: 8: 22: 70$ \\
\hline $\begin{array}{c}\text { 2\# Hardening agent + Lime fly-ash soil } \\
\text { (abbreviated as 2\# curing agent) }\end{array}$ & $0.2: 8: 22: 70$ \\
\hline $\begin{array}{c}\text { 3\# Hardening agent + Lime fly-ash soil } \\
\text { (abbreviated as 3\# curing agent) }\end{array}$ & $0.2: 8: 22: 70$ \\
\hline
\end{tabular}




\section{Analysis of material performance test}

\subsection{Compression test}

The compressive strength reflects the ability to withstand damage under external forces and is one of the most important mechanical indicators of hardened lime-ash pavement. Through the comparison of the compressive strength of three different kinds of mixtures of hardening agents and lime fly-ash, together with common lime fly-ash soil materials.

It can be seen from the above diagrams that the compressive strength of the lime-fly ash mixture with the addition of curing agent can be improved in varying degrees. Among them, the compressive strength for 7 days (abbreviated as 7d) and 28 days (abbreviated as 28d) unconfined saturated has been increased by an average of $184 \%$ and $40 \%$, respectively. It can be seen from Fig. 1 that the compressive strength of lime-lime soil is obviously improved after the addition of three kinds of low-concentration curing agents. Among them, the increase of the compressive strength of the $7 \mathrm{~d}$ mixture by adding the low concentration $2 \#$ curing agent is the largest, reaching $212 \%$. The compressive strength on $28 \mathrm{~d}$ mixture is increased by $49 \%$. The above indicates that the curing agent of $2 \#$ has the most remarkable effect in improving the compressive strength of the mixture.

By comparing Fig. 1 and Fig. 2, it can be seen that the compressive strength is correspondingly increased, when the concentration of the curing agent is increased. Among them, the $1 \#$ curing agent makes the strength increase of the $7 \mathrm{~d}$ lime fly-ash mixture by the largest margin, and the strength obviously increases with the increase of the concentration; $2 \#$ curing agent makes the strength of $28 \mathrm{~d}$ lime fly-ash mixture increase the most, but the increase in strength caused by the increase in the concentration is not significant. In general, the increase in the concentration of the curing agent has not significantly increased the strength of the mixture, indicating that the three curing agents at low concentrations have already improved the strength of lime fly-ash to a more desirable level. By way of increasing the concentration, the concentration has not been increased significantly. However, by increasing the concentration, the cost of the product will be doubled.

At the same time, it can be concluded from the figure that the hardening strength of the lime fly-ash soil with a curing agent is higher than that of the common lime-soil, and the increasing range of the $7 \mathrm{~d}$ compressive strength is greater than the $28 \mathrm{~d}$ compressive strength. This is mainly because active substances $\left(\mathrm{SiO}_{2}, \mathrm{Al}_{2} \mathrm{O}_{3}\right)$ in lime and fly ash have volcanic ash reaction in a relatively slow speed, and the self strength of $7 \mathrm{~d}$ lime fly-ash soil is relatively low. At this time, the proportion of the curing agent contribution to the overall strength is relatively large, thus making the mixture increase the strength at the early stage. It improves the defect of relatively slow strength formation for lime fly-ash stabilized materials and also lays a good foundation for the later-intensity formation of lime fly-ash soil.

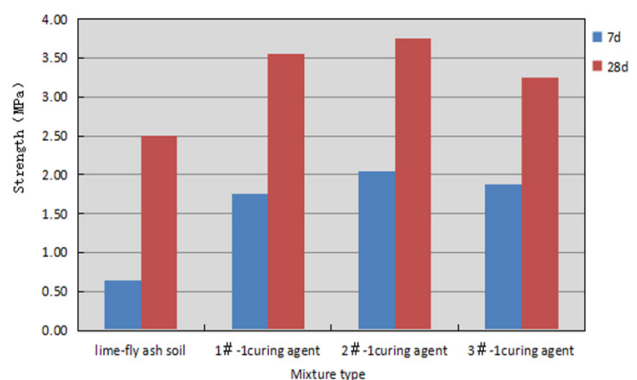

Fig. 1. Strength of highly concentrated hardener

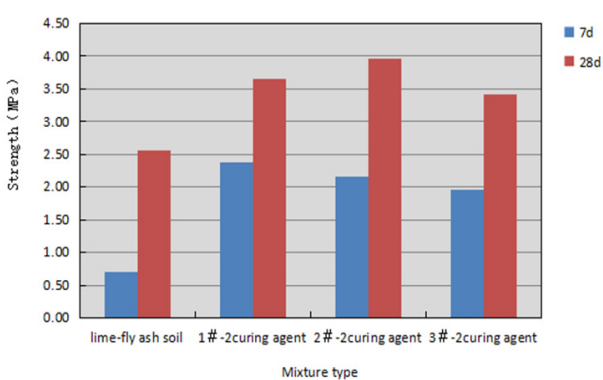

Fig. 2. Strength of lowly concentrated hardener

\subsection{Anti-pressure rebound modulus}

The modulus of resilience characterizes the ability of a material to resist deformation under 
external forces. A material with a large resilience modulus will produce less deformation under the same external force and have better mechanical properties.

From Fig. 3, it can be seen that the resilience modulus of the lime fly-ash mixture increases after the addition of the curing agent, and the increase of the $3 \#$ curing agent is the highest, reaching $46 \%$. This is due to the fact that the curing agent acts as a cementing agent in the mix, allowing the lime fly-ash material to be better bonded and form a unitary structure. Therefore, the hardened lime fly-ash mixture has better resistance to deformation than ordinary lime fly-ash soil.

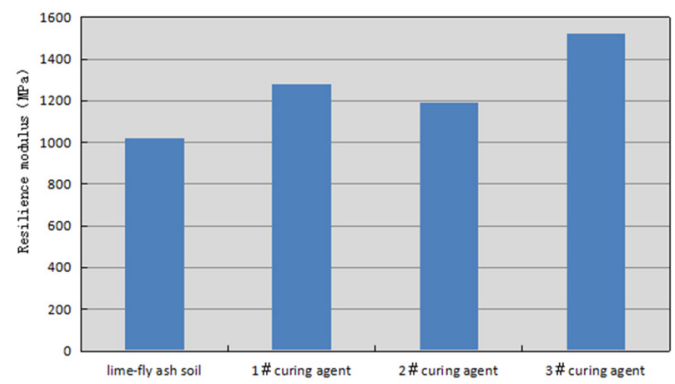

Fig. 3. Comparison of indoor resilience modulus

\subsection{Water stability}

Water stability is an important aspect of material stability. Because the hardened lime fly-ash pavement needs to be used on the surface of the road, the water stability of this material becomes even more important.

From the above figures, it can be seen that after the addition of the curing agent, the water stability coefficients of the lime fly-ash stabilized materials have improved to varying degrees. Among them, the $7 \mathrm{~d}$ and $28 \mathrm{~d}$ water stability coefficients have increased by an average of $65 \%$ and $56 \%$, respectively. It shows that the addition of the curing agent makes the coupling between the particles of lime fly-ash soil more compact, and effectively prevents the water from infiltrating the soil particle groups, thereby enhancing the strength and stability of the hardened lime fly-ash soil.

From Fig. 4 and 5, it can be seen that there is a small difference for the increased range of water stability coefficients concerning the mixtures of $7 \mathrm{~d}$ and $28 \mathrm{~d}$, when the three curing agents are at low concentrations. At high concentrations, 1\# curing agent showed a large increase in the water stability coefficients of blends $7 \mathrm{~d}$ and $28 \mathrm{~d}$, reaching $97 \%$ and $83 \%$. It shows that the high concentration of $1 \#$ curing agent has a good effect on improving the water stability of the lime fly-ash mixture. The comparison has found that the water stability coefficient of the mixture increases with the increase of the concentration of the curing agent, but the increase is not too large, which shows that when the concentration of the curing agent reaches a certain level, the water stability coefficient of the lime fly-ash mixture tends to stable.

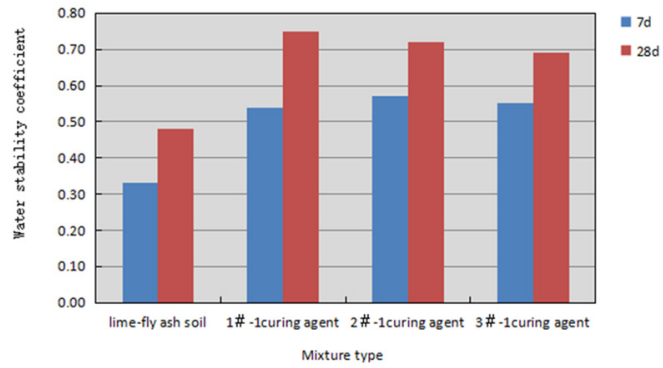

Fig. 4. Water stability (lowly concentrated hardener)

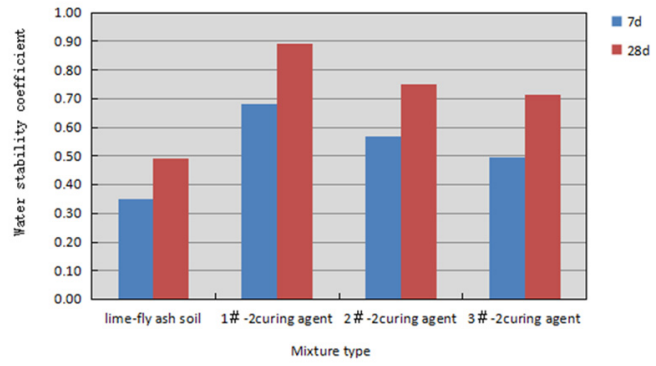

Fig. 5. Water stability (highly concentrated hardener) 


\subsection{Freezing stability}

The purpose of freezing stability test is to measure the change of strength of hardened lime fly-ash mixture under the repeated action of water and negative temperature, which is of great significance for the application of hardened lime fly-ash pavement in relatively cold areas.

Generally speaking, the freezing resistance of the material is related to the porosity of the material, the bonding strength between particles, the concentration of ions in liquid phase, and so on. Among them, the bonding strength between particles plays a major role in frost resistance. If the connection between particles is high and dense, it can effectively reduce the water immersion and resist the internal stress caused by frost heaving, and the material is not easy to destroy. The higher the frost resistance, the higher the freezing stability coefficient. It can be seen from Fig. 6 that the freezing stability coefficient of lime fly-ash mixture added with curing agent has been improved to a certain extent, in which the coefficient of freezing stability of mixture can be increased by 28 days and 90 days, by $26 \%$ and $24 \%$ respectively. It can be seen that $2 \#$ curing agent is better than the other two curing agents in improving the antifreeze property of lime fly-ash soil.

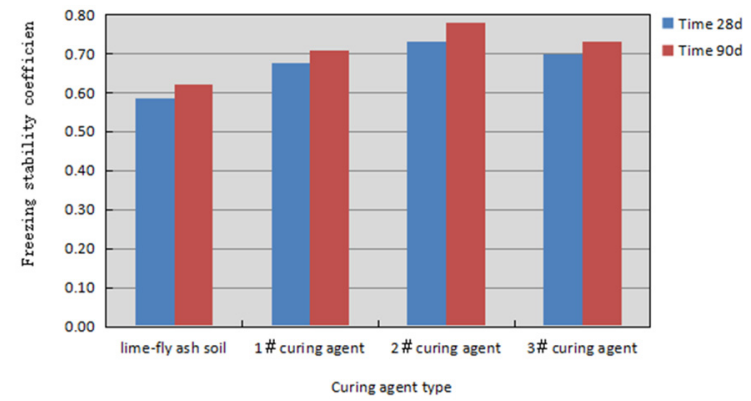

Fig. 6. Comparison of freezing stability coefficient

\section{Test road verification}

\subsection{Test road construction}

Considering that the hardened lime fly-ash pavement is mainly used for low-traffic roads in rural areas, the selection of raw materials and the selection of construction equipment are based on the status quo of rural highway construction, so that the road surface has the feasibility of being popularized in rural areas. The existing equipment in rural areas were utilized, such as agricultural vehicles, rotary tiller and vibratory roller, etc.

Raw materials include lime, fly ash, soil, stone debris and curing agent. The road mixing construction method is adopted $[10,11]$. The lime should be fully digested 7 days before use, and the ash mass and quicklime block should be removed. In order to prevent pollution caused by fly ash hoisting, the surface of fly ash heap should be kept moist, the water content of fly ash should be kept at $15 \%$ and $20 \%$; the engineering soil of the test road should be removed from large stones, branches, grass roots and other sundries before mixing. In order to ensure that the pavement has a certain wear resistance, after the mixture is compacted, a small amount of stone chips with particle size of 10-20 mm were added. As for construction machines and tools, it is advised to consider the use of rural local equipment, using agricultural vehicles, rotary tiller and vibratory roller, etc.

\subsection{Test road observation}

Three observations (one month, three months and six months) were conducted after the paving of the test road was completed. The overall effect and the specific conditions of the test road were 
investigated and observed, and the results were compared with ordinary roads of lime- fly ash soil. The results show as follows:

(1) Compared with ordinary lime-fly ash soil pavement, hardened fly ash pavement has better overall strength, so its smoothness is better and driving comfort is better.

(2) Due to the addition of curing agent, the water stability of lime-fly ash mixture has been greatly improved, so there is basically no rut. However, the rutting problem of the ordinary lime-fly ash soil pavement has been serious in the first observation. Moreover, the ordinary lime-fly ash soil pavement has been renovated in the third observation because it cannot be used normally.

\section{Conclusions}

1) Through mechanism analysis, the hardening effect of curing agent and the hydration reaction of fly ash and lime itself are the mechanism of the formation of the intensity of lime- fly ash road surface.

2) It is proved through indoor material tests that after adding the curing agent, the performance of the hardened lime-fly ash pavement material is significantly higher than that of ordinary lime-fly ash soil. It can basically meet the requirements for the use of low-traffic highway pavement in rural areas. This material can also be used in general highway bases with similar raw material areas.

3) Through the paving of the test road, it can be seen that the construction process of hardened lime-fly ash soil road surface is simple and reliable. It is very suitable for popularization in rural areas with similar raw materials and construction conditions.

4) It can be seen from the follow-up observation of the test road that the hardened lime-fly ash pavement has better smoothness, water stability and freezing stability than the ordinary lime-fly ash road surface. The hardened lime-fly ash pavement has good rutting resistance. Its road performance is obviously superior to that of ordinary lime-fly ash soil pavement. Without cement and asphalt binder, the road surface of rural highway can have good condition.

\section{References}

[1] Zhang Zhiqiang, Zhang Dehua, et al. Required Reading of Rural Highway Construction and Management. People's Communications Press, Beijing, 2004.

[2] Zhang Dengliang Principles of Reinforced Soil. People's Communication Press, Beijing, 1990.

[3] Matsuo Shinichiro Manual of Soil Reinforcement Method. China Railway Publishing House, Beijing, 1983, (in Japanese).

[4] Deng An Effects of different soil properties on the reinforcement performance of reinforced soil. Journal of Soil Engineering and Foundation, Vol. 2, 2001, p. 31-34.

[5] Liu Jianping, Zheng Yubin Polymer Science and Material Engineering Experiment. Chemical Industry Press, Beijing, 2005.

[6] Liu Wei, Chen Xiaoming Research on the synthesis and curing mechanism of polymer soil curing agent. Journal of Materials Science and Engineering, Vol. 2, 2002, p. 230-234.

[7] Yan Handong New Building Materials Course. China Building Material Industry Press, Beijing, 2005.

[8] Dong Yining, Xu Riqing, Gong Xiaonan Experimental study on solidifying agent ZDYT-1 for reinforcing soil. Chinese Journal of Geotechnical Engineering, Vol. 4, 2001, p. 472-475.

[9] Li Wenying, Dai Jingliang Research on reinforcing agent for reinforcing soil. Journal of Northeastern Highway, Vol. 1, 2003, p. 34-36.

[10] Li Maosong Lime-fly ash sub-base road mixing construction method. Shandong Communications Technology, Issue 3, 1997, p. 47-49.

[11] Xu Nengsheng Discussion on construction quality of lime-fly ash roadbed. Journal of Shandong University of Science and Technology, Vol. 3, 2003, p. 117-119. 